\title{
MARKeting político, DEMOCRACIA E CAPITALISMO
}

\author{
Sidney Tanaka de Souza Matos \\ Mestrando em Ciência Política pela UNICAMP \\ E-mail: sidney-tanaka@uol.com.br
}

\section{Resumo}

O presente artigo pretende analisar a utilização do marketing político nos processos eleitorais atuais a partir das origens não apenas do marketing político per se, mas relacionando sua prática e o desenvolvimento da idéia de democracia no século $X X$, que aproximou o conceito de democracia ao de uma simples luta competitiva pelos votos da população o que abriu caminho para a aplicação das técnicas de marketing aos processos eleitorais e analisando os alvos das maiores críticas atuais, como a despolitização e a superficialização das campanhas como produtos lógicos deste desenvolvimento do pensamento democrático.

Palavras-chave: democracia, eleições, marketing político

exemplo do ocorrido nos anos eleitorais recentes, o tema marketing político tem suscitado polêmica neste ano de 2002 em relação à sua utilização dentro do processo eleitoral, sendo atualmente um tema recorrente no meio acadêmico e mesmo na grande imprensa, como demonstra o destaque na cobertura jornalística da utilização do "marketeiro" Duda Mendonça (ex-publicitário de Paulo Maluf) pelo Partido dos Trabalhadores (PT) ou de toda a movimentação do Partido da Social Democracia Brasileira (PSDB) para cooptação do publicitário Nizan Guanaes, anteriormente responsável pela divulgação da, à época, pré-candidata à presidência da República Roseana Sarney.

As raízes do marketing político remontam, segundo Markun [19-], à vitória de Kennedy sobre Nixon em 1960, quando seu 
desempenho na série de debates na televisão americana foi decisiva. No Brasil, alguns autores chegam a localizar as primeiras tentativas de sua utilização ainda na década de 50 (GRANDI; MARINS; FALCÃO, 1992, p.35); porém, indiscutivelmente, foi após 1989, ano em que Fernando Collor de Mello foi eleito utilizando-se de um grande aparato publicitário, que este tema ganhou destaque que vem tendo nos dias atuais ${ }^{1}$.

Esta importância dada ao marketing político nos modernos processos eleitorais leva então à discussão sobre a sua interferência no processo democrático e sua real relevância na determinação do resultado final das eleições. Além destas questões, porém, para que haja um melhor entendimento da razão pela qual o marketing político assumiu tamanha importância na democracia atual, é necessário abordar o tema por um ângulo diferente, discutindo-o não apenas a partir do ponto de vista estrito das suas estratégias e efeitos, mas fazendo uma correlação-entre a sua genealogia e a da própria idéia de democracia disseminada na sociedade.

Ora, suas origens estão diretamente relacionadas, por um lado, às técnicas de marketing utilizadas no mercado capitalista de bens de consumo e, por outro, à existência dos governos representativos característicos das teorias liberais de democracia - o que implica, de modo bastante geral, na realização de processos eleitorais livres periodicamente. Estes fatos dizem muito a respeito de sua natureza intimamente relacionada ao desenvolvimento histórico do modo de

\footnotetext{
Além de ser um marco em relação às eleições no Brasil, a campanha de Fernando Collor de Mello à presidência da República em 1989 é bem ilustrativa da utilização do marketing político. A construção de sua imagem teve início muito antes da oficialização da candidatura pela Justiça Eleitoral. Através de uma eficiente estratégia de marketing, o então governador de Alagoas passou a ficar conhecido em todo o país, através da imprensa, como o "caçador de marajás e maior opositor do presidente José Sarney. Mais tarde, já candidato oficial à presidência, e com a imagem de "caçador de marajás" consolidada junto à opinião pública, passou a investir na imagem do jovem dinâmico, cosmopolita, que iria derrubar a inflação com um ippon, imagem que cultivou mesmo depois de eleito e que lhe valeu a comparação com Indiana Jones, feita por George Bush durante visita oficial de Collor aos Estados Unidos. Assim, a análise do fenômeno de Fernando Collor de Mello é bem didática, facilitando a compreensão do papel do marketing político e especialmente de suas conexões com os media no processo de construção da imagem do candidato.
} 
produção capitalista no ocidente, tanto no campo econômico quanto nas suas manifestações políticas e ideológicas. Um debate produtivo acerca do tema não pode, portanto, limitar-se ao estudo do modus operandi do marketing político, mas também deve levar em consideração seu processo de desenvolvimento dentro do panorama maior do desenvolvimento histórico do modo de produção capitalista no ocidente e de suas manifestações políticas, econômicas e ideológicas.

\section{Marketing político e democracia}

O conceito básico do marketing político apresenta-se - como, obviamente, não poderia deixar de ser - muitíssimo afinado com o conceito hoje amplamente aceito na Ciência Política de democracia como sistema político-institucional para determinação de líderes de um governo representativo, idéia esta cujas origens podem ser claramente traçadas nos desenvolvimentos da teoria democrática liberal no século $\mathrm{XX}$, e em especial na teoria democrática de Schumpeter. As bases destas idéias estão, por sua vez, relacionadas, como se verá adiante, com o desenvolvimento do modo de produção capitalista e a conseqüente hegemonia da burguesia na Europa e na América do Norte nos séculos XVIII e XIX.

O século XIX, em particular, é um marco no desenvolvimento deste pensamento democrático liberal, pois é somente aí que vai ocorrer a apropriação do conceito de democracia pela doutrina liberal ${ }^{2}$. Hobsbawn (1996) observa que esta apropriação ocorre em um momento em que as pressões das "massas", como os camponeses e a nova e crescente classe trabalhadora industrial, questionavam a política

\footnotetext{
2 Apesar de poder-se detectar idéias que poderiam ser identificadas com as teorias democráticas liberais,já no século XVII, como em Jefferson e em idéias associadas ao puritanismo, Macpherson observa que "a principal tradição ocidental até os séculos XVIII e XIX era não-democrática ou antidemocrática", ou seja, a participação popular na política era considerada incompatível com a sociedade liberal. Já Hobsbawn e Duverger, como será observado no corpo do texto, concentram suas observações a respeito da democracia liberal na questão da possibilidade ou impossibilidade de manter regimes que excluíssem as massas do processo político, o que se tornou impossível no século XIX.
} 
burguesa. A Revolução de 1848 na França demonstrava que essas massas numerosas poderiam sublevar-se contra o Estado burguês, o que forçou a abertura de espaços para a participação política dessas camadas da população, especialmente da crescente parcela dos trabalhadores industriais. Ademais, como observa o autor, o liberalismo, que formava a base da ideologia burguesa, ao defender os ideais de igualdade legal, não tinha justificativa para opor-se a essas demandas de participação popular na política.

Este avanço dos governos representativos na maior parte da Europa e na América do Norte (Estados Unidos) seria, deste modo, corolário da forma de hegemonia da burguesia na sociedade ocidental porque, ao contrário da aristocracia feudal ou do monarca absoluto, cujo poder era baseado em uma rígida hierarquia estamental, a burguesia necessitava angariar o apoio das massas, uma vez na medida em que seu poder não se fundava em instituições que poderiam, como coloca o autor, "salvaguardá-la" do voto. A própria ideologia burguesa tornava essa salvaguarda impraticável, visto que defendia a liberdade individual e a igualdade legal de todos os indivíduos, e portanto, era incompatível com o total afastamento das massas do processo político.

Assim, em um contexto social no qual a burguesia não tinha como manter um regime autocrático, tanto pelo crescente movimento de emancipação popular que caracterizou o final da era feudal quanto pela impossibilidade ideológica de manutenção de um regime de tal natureza, a organização de regimes representativos constituía-se a forma pela qual a burguesia manteria a hegemonia na sociedade, combinando a idéia da necessidade de preservação da liberdade individual corporificada em direitos pessoais inalienáveis, cara ao pensamento liberal $^{3}$, com a participação política ampliada das massas.

\footnotetext{
${ }^{3}$ Essa preocupação com o governo não-despótico pode ser já bem observada no final do século XVII na obra de Locke(1983). No "Segundo Tratado Sobre o Governo Civil", Locke vai justificar a Revolução Gloriosa na Inglaterra, com base no direito de resistência; no qual, partindo do princípio que somente o consentimento do povo dá legitimidade ao governo e que este tem por função a defesa da propriedade e a proteção contra inimigos internos e externos; quando o governo atenta contra a propriedade (tida enquanto direito natural) ou viola as leis estabelecidas, este entra em conflito com a sociedade que o constituiu e que tem o direito de resistência à sua tirania.
} 
Esta identificação da democracia com o governo representativo levou, por sua vez, ao desenvolvimento de um sistema político no qual enfatizada a necessidade de, por um lado, estabelecer regras de acesso ao poder de Estado e, por outro, controlar e limitar o poder deste Estado como forma de garantir a autodeterminação individual. Esta ênfase no controle dos limites do Estado e na instrumentalização de regras de acesso ao poder levará, ao longo do século $\mathrm{XX}$, ao desenvolvimento de teorias democráticas caracterizadas pelo esvaziamento do caráter de participação popular na política.

Ademais, Pateman (1992) cita também o aparecimento e a sofisticação da sociologia política no século XX e a emergência de Estados autoritários na Europa do primeiro pós-guerra como fatores determinantes para o desenvolvimento dessas teorias de perfil minimalista.

O desenvolvimento da Sociologia Política é visto por ela dentro de um panorama de complexização da sociedade industrial e do desenvolvimento das formas de organização burocratizadas que marcaram o final do século XIX e início do século XX, que levaram a um certo ceticismo por parte dos teóricos da época em relação à viabilidade dos ideais democráticos, citando Mosca e Michels como os mais influentes nesta linha de pensamento. Mosca, adepto de uma teoria elitista de governo, colocava a necessidade de uma elite no poder em uma sociedade burocratizada, enquanto Michels, partindo do estudo dos partidos social-democratas alemães, desenvolveu a chamada "lei de ferro da oligarquia"4.

A emergência dos regimes totalitários trouxe a preocupação com destinos da democracia: o que aconteceria caso fosse permitida a participação política da grande massa populacional, tendo em vista o grande apoio popular que respaldou a ascensão dos regimes nazifascistas e totalitários no primeiro pós-guerra.

Além da constatação de que a maior parcela da população, em especial os grupos de mais baixo nível social, demonstra pouco

\footnotetext{
"A "Lei de Ferro da Oligarquia" de Michels parte de uma concepção onde a necessidade de organização leva à transformação de toda estrutura partidária em uma organização oligárquica.
} 
interesse por política, tem-se um panorama que leva ao desenvolvimento de teorias em que há um esvaziamento do significado da democracia no seu sentido original, ou seja, o poder de decisão popular sobre a sociedade em que vive e o direito de influir nas decisões que dizem respeito à coletividade, é muitas vezes reduzido à simples participação eleitoral.

Dentro desta linha de pensamento liberal-democrática que se desenvolve no século $\mathrm{XX}$, a teoria que mais vai influenciar o pensamento político, sendo uma das bases da atual concepção de democracia do mainstream da Ciência Política é, sem dúvida nenhuma, a desenvolvida por Schumpeter. Como coloca Bottomore, "ele formula uma definição econômica de democracia, concebida como um arranjo institucional semelhante ao mercado, em que vários grupos e indivíduos equivalentes a empresas e empresários - competem entre si pelos votos dos eleitores [...]" (apud SCHUMPETER, 1984, p.12).

Partindo de uma visão pretensamente empírica do problema da constituição do "método político"5, Schumpeter refuta as teorias políticas do século XVIII que se assentavam em torno da idéia de bem comum e vonlunté générale, pois considera que essas idéias - que formam a base do pensamento democrático liberal daquele século - não podem ser consideradas concretamente, visto que não há um conceito de bem comum unicamente determinado e percebido por todos os indivíduos. Refutando estas idéias, desenvolve, então, uma teoria na qual o "método democrático" é colocado apenas e tão somente como um acordo institucional para produzir um governo através da luta competitiva pelos votos da população.

Essa visão mercadológica do processo democrático reduz a participação da população no método democrático à função de determinação (através de eleição com voto livre) do governo, direta ou indiretamente (assim como o direito de desapossá-lo); retirando-lhe, porém, a capacidade de definição racional de seus objetivos e da escolha de seus representantes, pois, para Schumpeter (1984, p.328-329), "a vontade do povo é o produto e não o motor do processo político".

"Conceituado como " o método que uma nação usa para chegar a decisões" (SCHUMPETER, 1984, p.305) 
Para ele a democracia é uma disputa competitiva entre elites pelos votos da população- o que pressupõe necessariamente a existência de liberdades civis que garantiriam o voto livre dos eleitores - cuja maioria é pouco informada e pouco interessada nas questões específicas do campo político, (o "cidadão típico cai num nível mais baixo de desempenho mental"). Assim sendo, as decisões dessa maioria seriam baseadas na falta de senso racional e na afetividade e os variados grupos com interesses políticos ou econômicos podem influenciar muito amplamente e até determinar a vontade popular.

Com essa visão, Schumpeter retira do processo democrático toda idéia de uma atuação em torno de meios e fins, o que esvazia a idéia original de "governo do povo", "bem comum" ou o "governo da maioria", para um simples método de escolha de governo, em que sua participação consiste, em última instância e segundo suas próprias palavras, na "aceitação de um líder ou grupo de líderes" em que o controle que o eleitorado exerce sobre os líderes se dá apenas no processo eleitoral e na possibilidade de recusa de reeleição de uma elite. Isto implica no abandono da idéia que fundamenta todo o pensamento político democrático ${ }^{6}$ anterior a ele, que é a idéia da racionalidade da ação política. Ao indivíduo comum é negada a capacidade de ação racional; seu comportamento político é baseado em preconceitos e impulsos e não há, por parte dele, controle lógico efetivo sobre o seu resultado.

O locus da racionalidade do processo político aí é bem localizado: são as elites que competem pelos votos desta população preconceituosa, impulsiva e influenciável. Estas elites vão lutar pela defesa de seus interesses, tentando cooptar a maior parcela possível dos indivíduos em prol desses interesses de forma a angariar votos e implementar estes interesses quando assumirem o governo.

Assim, a preocupação dos teóricos liberais do século XIX com a preservação da liberdade individual frente ao crescente poder do Estado - que se tornava cada vez mais burocratizado e poderoso dentro

"E mesmo na teoria política anterior ao pensamento democrático liberal, cujo exemplo mais óbvio é Hobbes, que, mesmo no estado de natureza caracterizado pela violência, atribui a ação individual à racionalidade. 
da sociedade industrial - evolui no século XX para teorias que se concentram em um sistema político autônomo em que a participação da população se reduz ao ato do voto ou então se torna uma disputa entre elites que competem entre si em um jogo político que canaliza os conflitos para o sistema político.

Fica claro também o rompimento com a idéia básica nas teorias democráticas liberais do século XIX - originária do pensamento iluminista que está na base do desenvolvimento da ideologia burguesa - da racionalidade do comportamento político do ser humano; assim como da teoria utilitarista de Benthan, considerada um marco no desenvolvimento da teoria democrática do século XIX, a qual tem por base a procura individual da maximização da felicidade, tomada como a quantidade de prazer individual menos a de sofrimento (o que comporta necessariamente uma idéia de ação visando um fim preestabelecido e, portanto, uma idéia de racionalidade da ação humana). O mesmo acontece com a preocupação de Stuart Mill (1964) com a constituição do "bom governo" - cujo papel principal é a promoção da virtude e da inteligência, com vistas à constituição de uma sociedade equilibrada o que comporta também a idéia da ação racional quando do estabelecimento do fim do "bom governo", por um lado, e, por outro, quando estabelece o princípio ético implícito no conceito do "bom governo" - chega-se no século XX às teorias que, se não retiram totalmente das massas a capacidade de compreensão do processo político e, portanto, a capacidade de sua ação racional, centralizam esta capacidade nas elites políticas que vão lutar pela defesa de seus interesses, através da tentativa de convencimento das massas de que estes interesses são gerais, conquistando com isso seus votos para assumirem o controle da máquina do Estado.

Assim, estes dois fatores característicos do pensamento democrático moderno a visão da democracia como sistema de escolha e legitimação de líderes (o que traz implícita uma idéia de "jogo" ou "disputa" muito próxima da idéia da competição no livre-mercado capitalista), e a negação de uma racionalidade política substantiva das massas (e portanto a possibilidade de "produção" de sua vontade, visto que ela perde sua capacidade de ação visando um fim claramente identificável), além do enfraquecimento do princípio ético do governo 
democrático, tornam-se fatores determinantes e até mesmo naturalizam a elevação do marketing político ao seu atual nível de importância dentro do processo eleitoral.

\section{Marketing, política e mercado}

O marketing é um produto do desenvolvimento do capitalismo monopolista no século XX e, apesar de seus modernos conceitos e técnicas terem surgido na década de 60 , com Kotler, suas origens remontam à primeira metade desse século, quando começavam a surgir os primeiros estudos sobre o comportamento do consumidor; tributários do desenvolvimento da nova teoria do valor da escola marginalista de economia a partir de 1870, quando Karl Menger rompe com a teoria clássica do valor-trabalho e passa a defini-lo pela "utilidade", enquanto capacidade de satisfazer às necessidades subjetivas do ser humano.

Fundamentado na idéia de adaptação dos produtos a estas necessidades subjetivas dos consumidores no mercado capitalista de bens, o marketing constitui-se, basicamente, de um conjunto de técnicas de lançamento planejado de produtos neste mercado. Estas técnicas matemáticas, estatísticas, econômicas, sociológicas e psicológicas visam, por um lado, buscar indicações destas necessidades - reais ou imaginárias - dos consumidores através da pesquisa e análise de mercado e, por outro, a promoção da venda desses produtos através de seu lançamento no mercado (estruturação da produção e distribuição do produto) e da persuasão dos consumidores (através da publicidade e do merchandising); e com isso maximizar sua presença no mercado e, conseqüentemente, a lucratividade do produto.

Seguindo os preceitos básicos desenvolvidos pelo marketing utilizado no mercado capitalista de bens, o marketing político levou a grandes modificações na forma de condução das campanhas políticas, com o surgimento de profissionais altamente especializados no ramo. O planejamento e a execução das campanhas eleitorais passaram a ser feitos por equipes multidisciplinares que analisam a disputa eleitoral a partir da ótica dos processos mercadológicos, que pressupõem a existência de um "mercado" eleitoral, no qual os candidatos e eleitores 
se relacionam. Ou seja, um "mercado eleitoral" em que eleitores, em procedimentos similares aos consumidores no mercado capitalista, buscam a satisfação de suas necessidades; e os candidatos, por sua vez, buscam adequar-se, aos olhos dos eleitores, aos parâmetros de satisfação destas necessidades, conquistando, assim, votos.

Assim, o "marketeiro", antes mesmo do lançamento oficial da campanha, analisa este "mercado", buscando captar suas "necessidades" e tendências de comportamento. Para isso, lançam mão de pesquisas de opinião pública, quantitativas e qualitativas, que levam em conta o histórico de comportamento eleitoral de cada área geográfica, associando-o às características socioeconômicoculturais da população. Paralelamente, realizam estudos antropológicos com a finalidade de definir as motivações do voto de cada grupo socio-geográfico, avaliando suas aspirações e preocupações para, assim, determinar os problemas que mais sensibilizam cada parcela do eleitorado, bem como o perfil de político desejado e as potencialidades do candidato.

A partir dessa avaliação, os "marketeiros" podem, através da análise dos dados obtidos, definir o perfil que o candidato deve encarnar para estar em sintonia com as tendências do "mercado" eleitoral, indo, o perfil adotado por esse candidato porta-se, no tempo e no espaço, de acordo com as tendências deste "mercado" eleitoral.

Essa avaliação permite ainda o planejamento da campanha propriamente dita, dando subsídios para a determinação do públicoalvo do candidato, bem como do discurso adequado a cada segmento socioeconômico, para que não se tenha a rejeição dos demais. Constróise, assim, uma imagem do candidato mais apta a conquistar este mercado cujo perfil foi levantado e analisado minuciosamente. Nesta construção da imagem do candidato, os organizadores da campanha não vão pautar pelas suas posições ideológicas, mas vão adaptá-las e apresentá-las ao público de acordo com as tendências do "mercado".

Dessa forma, o fio condutor das campanhas passa a ser as tendências do "mercado" eleitoral. Diluindo os elementos ideológicos e políticos do processo eleitoral, o embate migra do campo da ideologia política para o campo publicitário. Por isso, a publicidade é um dos elementos-chave dentro da estratégia global do marketing político, constituindo-se a grande preocupação da 
equipe de planejamento da campanha: uma boa estratégia de divulgação pública, associada ao perfil adequado de candidato, é a chave para uma boa votação no pleito ${ }^{7}$.

Não é por acaso, assim, a utilização extensiva do elemento publicitário e o esvaziamento do debate ideológico na condução das modernas campanhas eleitorais. A identificação do candidatomercadoria que decorre do marketing político dilui os elementos substantivos do debate político-ideológico, reduzindo-os a meros slogans que são transmitidos da forma mais impactante e atraente possível, de forma a atrair a atenção do eleitor-consumidor.

Ademais, para além do aspecto específico da divulgação do candidato-mercadoria, esta redução do debate político a slogans impactantes que caracteriza o elemento publicitário é, em um nível mais profundo, resultado direto da própria concepção de tempo que se desenvolve com o modo de produção capitalista, quando começa a surgir uma crescente preocupação com a quantificação e otimização da utilização do tempo nos processos de trabalho e cujo maior exemplo são os estudos sobre ritmo e padronização do trabalho de Taylor (1978). Sob o capital, "tempo é dinheiro", que se torna elemento fundamental do processo de produção de mercadorias e, como resultado desta concepção, acelera-se o ritmo dos processos de trabalho e, conseqüentemente, o ritmo de todos os aspectos da vida social, que se organiza em torno do processo de acumulação de capital ${ }^{8}$, levando à constante busca de melhor aproveitamento do tempo.

E, dentro deste perfil publicitário das modernas campanhas políticas, os media ${ }^{9}$ assumem extrema importância para o candidato-

\footnotetext{
${ }^{7}$ As estratégias de divulgação pública utilizadas na construção da imagem do candidato frente à opinião pública não se restringem, porém, somente às formas tradicionais de publicidade política, mas também utilizam-se de formas menos óbvias de convencimento da população, como a geração de fatos políticos que influenciem positivamente a construção da imagem do candidato, divulgando-a em espaços considerados imparciais, como a grande imprensa; veja, por exemplo, o caso do "caçador de marajás".

* Deve-se anotar aqui também a questão da alienação que decorre da divisão de trabalho capitalista e da consequente aceleração dos ritmos de trabalho, porém este tópico não será desenvolvido neste ensaio.

"Meios de comunicação de massa.
} 
mercadoria, possibilitando a ele atingir simultaneamente grandes contingentes populacionais espalhados por todo território nacional, especialmente os media eletrônicos que podem cobrir simultaneamente, via satélite, todo o território nacional, de maneira instantânea, e com a vantagem adicional sobre as media escritos, podendo transmitir sua mensagem a um contingente mais amplo de eleitores-consumidores, como os analfabetos, por exemplo. Assim, a estratégia de divulgação publicitária do candidato, ou futuro candidato, ganha dimensões nacionais, ao contrário do que ocorre quando da utilização dos atos públicos, que se constituem atos restritos, de repercussão apenas local e sobre um público pequeno, se comparado ao público potencial da divulgação através dos media.

$\mathrm{E}$, em virtude do imperativo da maximização do aproveitamento do tempo e da conseqüente aceleração dos ritmos da vida social característicos do modo de produção capitalista e a organização dos governos representativos em âmbito muito maior que os pequenos governos locais, com a necessidade, portanto, de atingir maiores contingentes populacionais dentro de prazos legais definidos, é possível verificar a conexão entre a importância assumida pelos media nos processos eleitorais modernos e o próprio desenvolvimento dos regimes e do pensamento liberal democrático no século $\mathrm{XX}$.

E dentre os media eletrônicos, deve-se destacar o papel da televisão, dado seu alto grau de massificação na sociedade atual. A linguagem televisiva, se consideradas suas características de alta velocidade e alto ritmo de troca de imagens - que têm relação com o custo publicitário da transmissão televisiva (o volume de imagens atraentes deve ser constante para manter a audiência da emissora e, conseqüentemente, manter seu prestígio e rentabilidade) - reforça ainda mais a tendência ao enfraquecimento do elemento político-ideológico, à medida que potencializa características como a superficialização dos fatos, o reforço ao esquecimento e a recepção acrítica das imagens que passam de maneira acelerada frente aos olhos do eleitor-consumidor.

Além disso, a utilização extensiva dos media também contribui para o enfraquecimento do elemento político-ideológico resultante da utilização do marketing político num outro sentido: à medida que o eleitor não necessita recorrer ao espaço público (comícios, sindicatos, 
associações, etc.) para tomar conhecimento dos acontecimentos políticos, acentua o elemento privado da participação popular no processo eleitoral. Com isto, embora ainda permaneçam ativos fatores ideológicos e um certo grau de pressão social na escolha do eleitor, esses fatores têm sua importância diluída pela transposição do processo eleitoral do espaço público para o privado.

Deve-se notar que este aspecto vai ao encontro do caráter individualista do pensamento liberal. Ora, o liberalismo deriva sua concepção da sociedade do comportamento e das preferências do indivíduo. Nada mais natural, portanto, que os espaços privados fossem ganhando importância crescente no desenvolvimento dos modernos processos eleitorais, tanto pelo desenvolvimento e barateamento da tecnologia de informação, que possibilitou a massificação de seu consumo, quanto pela pulverização do eleitorado pela concepção individualista de sua participação.

Fica claro, portanto, que não é coincidência o alto grau de referencialidade da moderna publicidade política com a publicidade de produtos em geral, cujo exemplo recente mais evidente foi o comercial, criado pelo já citado Nizan Guanaes, da ex-pré-candidata à presidência da República Roseana Sarney, que é todo ele uma clara alusão a uma marca de cerveja bastante conhecida no Brasil, e mediante o qual, referindo-se ao resultado de uma pesquisa de opinião pública na qual a pré-candidata do PFL na época teve o maior índice de popularidade entre os governadores pesquisados, parodia-se o jingle da cerveja ("a Roseana é a $\left.n^{\circ} 1^{\prime \prime}\right)$. Esta referencialidade é, na verdade, uma consequêencia lógica da utilização do marketing político, dada sua origem no marketing para o mercado capitalista de bens, equiparando eleitores a consumidores e candidatos a mercadorias.

\section{Conclusão}

Ao abordar-se o tema do marketing político e as campanhas eleitorais modernas, não é suficiente, portanto, restringir as análises aos efeitos imediatamente perceptíveis de sua utilização. É necessário, antes de tudo, analisar as origens do marketing político 
e as origens da própria idéia de democracia que é percebida pela sociedade em geral.

Ora, como foi possível observar, o desenvolvimento da idéia de democracia no decorrer do século XX levou a uma concepção de democracia instrumental, calcada na sistematização da disputa eleitoral com vistas à escolha de líderes. Esta concepção, fortemente derivada das concepções schumpeterianas, aproxima, por um lado, a atividade política da concorrência no mercado capitalista de bens, o que esvazia o conceito de democracia de suas conotações mais substantivas, reduzindo-a a uma simples disputa entre elites concorrentes pelo controle do governo que tem como questão principal o estabelecimento de regras de disputa eleitoral garantidoras da "livre-concorrência" das várias elites, e, por outro, retira, em grande parte, a capacidade de entendimento substantivo da política (afetando, portanto, sua capacidade de ação racional) por considerável parcela da população, que passa a ser considerada fortemente influenciável, preconceituosa e passional e, portanto, passível de convencimento e de direção de suas ações. Esta nova idéia de democracia, profundamente afeita à lógica do mercado capitalista, abre as portas para o surgimento do marketing aplicado à disputa eleitoral nas mesmas bases da aplicação do marketing no mercado capitalista de bens. Portanto, mais do que um elemento de desvirtuamento do processo democrático, o marketing político é resultado natural do desenvolvimento da idéia de democracia no século XX. É sua própria redução à simples idéia de sistema eleitoral competitivo que vai abrir espaço para a utilização das técnicas de marketing nesta disputa.

Além disso, seus efeitos de despolitização e superficialização não podem ser analisados fora deste contexto. Tendo surgido do marketing para o mercado capitalista de bens, o marketing político não poderia ter efeitos diferentes em sua aplicação às disputas eleitorais. Ele vai equiparar candidatos a mercadorias a serem vendidas no mercado eleitoral competitivo e, buscando influenciar os consumidores (essas massas influenciáveis, preconceituosas e passionais), vai tentar apresentar seu produto da forma mais atraente possível, diluindo os elementos substantivos do debate político-ideológico em slogans transmitidos à audiência da forma mais atraente possível. 
Portanto, antes de se questionar a utilização do marketing político, é necessário que se questione o próprio conceito de democracia da sociedade, pois este nada mais é do que o produto lógico do desenvolvimento da idéia de democracia na forma que ele se deu no século XX e continua sendo dominante nos dias de hoje.

\section{Referências}

GRANDI, R.; MARINS, A.; FALCÃO, E. (Org.). Voto é marketing: o resto é política. São Paulo: Edição Loyola, 1992.

HOBSBAWN, E. J. A era do capital. Rio de Janeiro: Paz e Terra, 1996.

LOCKE, J. Segundo tratado sobre o governo civil. São Paulo: Abril Cultural, 1983. (Coleção Os Pensadores).

MARKUN, P. Como perder as eleições (ou táticas e estratégias para evitar que isso aconteça). São Paulo: Feeling Editorial, [19-].

MILL, J. S. Governo representativo. São Paulo: Ibrasa, 1964.

PATEMAN, C. Participação e teoria democrática. Rio de Janeiro: Paz e Terra, 1992.

SCHUMPETER, J.A. Capitalismo, socialismo e democracia. Rio de Janeiro: Zahar, 1984.

TAYLOR, F.W. Princípios de administração científica. São Paulo: Atlas, 1978. 


\begin{abstract}
This article intends to analyze the use of political marketing in current political processes not from its origins itself, but relating its pactice and the development of democratic idea in $20^{\text {th }}$ century, wich get it closer to idea of a simple competition for population votes, what makes possible the aplication of marketing techniques to electoral processes and analyzing the subjects of the largest current critics, like depolitization and superficiality of campaigns as logical products of this kind of democratic thought development.
\end{abstract}

Key words: democracy, elections, political marketing 